\title{
CHOLINESTERASE INHIBITORY AND ANTIOXIDANT ACTIVITIES OF THAI TRADITIONAL REMEDIES POTENTIALLY USED FOR ALZHEIMER'S DISEASE
}

(C) Tappayuthpijarn P. ${ }^{1}$, Sattaponpan C. ${ }^{2}$, Sakpakdeecharoen I. ${ }^{1}$, Ittharat A. ${ }^{1}$

${ }^{1}$ Applied Thai Traditional Medicinal Medicine

${ }^{2}$ Research Center, Faculty of medicine, Thammasart University, Rangsit campus, Klong Luang, Pathumthani, 12120, Thailand

At present, cholinesterase inhibition and neuronal protection from oxidative stress are well-known mechanisms that widely used for the treatment of Alzheimer's disease $(A D)(1,2)$. According to Thai traditional medicine, brain hypo-function, which has similar symptoms to that of $A D$, was due to declining in Dhatu-wind, blood circulation and neurological system. Trikatuk is herbal remedy, strongly increases Dhatu-wind, had been used as nootropic remedy for body balance in rainy season. It's composed of 3 plants: Zingiber officinale rhizomes (Zo), Piper nigrum fruits (Pn) and Piper retrofractum fruits $(\mathrm{Pr})$ in either ratio of $1: 1: 1$ (Tk1), 3:2:1 (Tk2), 1:3:2 (Tk3) or 2:1:3 (Tk4). This study focused on acetylcholinesterase (AChE) and human butyrylcholinesterase (BuChE) inhibitory activities by the method of Elman $(3,4)$ and antioxidant activity by DPPH method (5) of the 4 remedies and ingredients. Sixty grams of each plants and recipes were extracted by $95 \%$ ethanol $(250 \mathrm{ml} \times 3)$, then evaporated under reduced pressure and dried in vacuum-dry at $45{ }^{\circ} \mathrm{C}$ for 24 hour. Piperine and 6-gingerol of each extracts were also determined by HPLC. The results showed that the ethanolic extract of the 4 remedies at dose of $0.1 \mathrm{mg} / \mathrm{ml}$ had BuChE inhibitory effect more than $70 \%$. The $\mathrm{IC}_{50}$ of AChE inhibitory activity of Zo, Pn, Pr, Tk1, Tk2, Tk3, Tk4, galantamine were $>300,25.46,51.60$,
$45.6,51.97,41.19,42.93,0.1 \mu \mathrm{g} / \mathrm{ml}$ and that of BuChE were $60.82,42.94,34.58,28.74,25.39,35.01,33.28$, $0.37 \mu \mathrm{g} / \mathrm{ml}$ respectively. All Trikatuk remedies exhibited higher BuChE inhibitory activity than that of AChE. The Tk1 and Tk2 exhibited higher BuChE inhibitory activity than single herb. The antioxidant activity of Zo and Tk2 were 16.59 and $48.80 \mu \mathrm{g} / \mathrm{ml}$ which were higher activity than the others. The percentage of piperine and 6 -gingerol in Tk2 extract $(\mathrm{w} / \mathrm{w})$ were 18.57 \pm 0.22 and $1.05 \pm 0.01 \mathrm{mg} / \mathrm{g}$. The combined recipes had synergistic effect on BuChE inhibitory activity more than single herb. In addition, the Tk2 might protect neuronal cell from oxidative stress toxicity due to its antioxidant effect. These results revealed that Tk2 was the potential use for AD treatment.

References: (1) Raina P, et al. (2008). Ann Intern Med.148: 379-97. (2) Ebrahimi A, Schluesener H. (2012). Ageing Res Rev. 11 (2): 329-45. (3) Elman G, et al. (1961). Biochem Pharmacol. 7: 88-95. (4) Ingkaninan K, et al. (2003). J Ethnopharmacol. 89: 261-4. (5) Yamasaki K, et al. (1994). Chem Pharm Bull. 42:1663-5.

Acknowledgments: This work was supported by the Higher Education Research Promotion and National Research University Project of Thailand, Office of the Higher Education Commission

\section{THE EFFECT OF MORINGA OLEIFERA L. ESSENTIAL OIL ON ORAL PATHOGENS}

\section{(C) Thaweboon Boonyanit, Thaweboon Sroisiri}

Faculty of Dentistry, Mahidol University, Bangkok, Thailand

Essential oil extracted from Moringa oleifera L. seeds was assayed for the evaluation of antimicrobial activity against oral pathogens. Oral pathogens used for the evaluation were Streptococcus mutans KPSK2, Lactobacillus casei ATCC 6363, Candida albicans ATCC 10231, Porphyromonas gingivalis W50, Actinomyces israelii ATCC 10048 and Actinomyces viscosus (clinical isolate). The microbial growth inhibitory potential of the oil was initially determined using agar disk diffusion method. Then the minimum inhibitory concentration (MIC) values were also evaluated by agar dilution method. Essential oil extracted from
$M$. oleifera seeds has antimicrobial activity against $C$. albicans, $P$. gingivalis, $A$. israelii and $A$. viscosus with the zones of inhibition ranging from 10 to $13 \mathrm{~mm}$. MIC values for $C$. albicans, $P$. gingivalis, $A$. israelii and A. viscosus were $3.12,0.32,0.39$ and $0.78 \% \mathrm{v} / \mathrm{v}$, respectively. No inhibitory effects were observed on $S$. mutans and $L$. casei. Essential oil extracted from $M$. oleifera seeds can inhibit the in vitro growth of some oral pathogens. It appears to be a promising source of new alternative antimicrobial agent that may be used for the prevention or treatment of some oral infections. 